\title{
THYROID CARCINOMA IN CHILDHOOD IN GREAT BRITAIN
}

\author{
BY \\ KEITH D. ROBERTS \\ From the Children's Hospital, Birmingham
}

(RECEIVED FOR PUBLICATION NOVEMBER 19, 1956)

Carcinoma of the thyroid in childhood is a rare condition, and after an extensive search only seven cases have been found in Great Britain.

In 1920 Hughes dissected enlarged cervical glands in a 13-year-old girl; the glands were found to be invaded by papilliferous thyroid carcinoma and thyroidectomy was done. The child was well three months later.

Moncrieff and Poynton (1929) reported the case of an 11-year-old girl who had had a swelling of the neck since the age of 4 , with recent enlargement and respiratory obstruction. Removal was attempted but the child died; post-mortem examination showed a carcinoma of the thyroid, partly solid and partly papilliferous, and infiltrating the trachea.

Taylor and Wilkinson (1935) reported a 6-year-old girl who had a cough for five weeks, dyspnoea, but no haemoptysis, after a cold. There were small, discrete, hard cervical glands, and a radiograph of the chest showed appearances suggestive of miliary tuberculosis but the Mantoux reaction was negative. During the next two months the glands enlarged and fused, producing stridor, increasing dyspnoea from tracheal compression and eventually death from asphyxia. Post-mortem examination showed a partly solid, partly papillary carcinoma of the thyroid, infiltrating the trachea and invading the cervical glands. The lungs were studded with metastatic deposits.

d'Abreu (1936) treated a girl of 16 who had had a swelling in the neck associated with a 'choking' feeling for three months; biopsy of a gland in the left anterior triangle showed infiltration with adenocarcinoma. Subsequently left hemithyroidectomy and dissection of the remaining glands was done, and when seen nine years later she was married, with a family, and had had no recurrence.

Joll (1936) removed an adenocarcinoma of the thyroid in a 16-year-old girl. Three courses of radiotherapy, with a total dose of $2,400 \mathrm{r}$ on each occasion, were given and she has remained well.
Goldie (1950) examined an operation specimen from a 12-year-old boy; he had had a swelling of the thyroid excised one year before, and the swelling had recurred. The gland was greatly enlarged and both lobes contained multiple nodules; some of these were composed of undifferentiated epithelial cells, some showed papillary structure and others mixed solid and papillary elements. Atypical cells and mitoses were found towards the periphery of the nodules.

East (1954) treated a 14-year-old girl who had had a large gland in the left upper cervical chain for four years; the gland was excised and shown to be infiltrated with papillary adenocarcinoma. Subsequently total thyroidectomy was done, and the left lobe contained a papillary and tubular colloidsecreting adenocarcinoma. Professor Smithers subsequently investigated her with radioactive iodine but found no reason for treating her with it. Three months after operation enlarged cervical glands were found and removed from both sides. Two months later enlarged supraclavicular glands were noted, and Professor Smithers gave a course of radiotherapy, $3,700 \mathrm{r}$ in 39 days. The child has since remained well, with no recurrence after one year.

Winship and Chase (1953), have commented on the paucity of reported cases of carcinoma of the thyroid in children in western Europe, and could collect only 42 . Winship (1951) also indicated that inadequate follow-up and deficient hospital records hinder the evaluation of therapy for a condition of high mortality in children, emphasizing the importance of early diagnosis and the radical removal of all nodular goitres. It is therefore felt that the following case should be recorded.

\section{Case Report}

S.L., a boy of 9 years, was congenitally deaf and had been having speech therapy for five years. A swelling of the neck had been noticed for two years, but his mother did not seek advice until tonsillitis one month previously had seemed to cause an increase in the size of the swelling. 
Fig. 1.-Adenomatous area of thyroid.

FIG. 2.-Adenocarcinomatous nodule of thyroid.
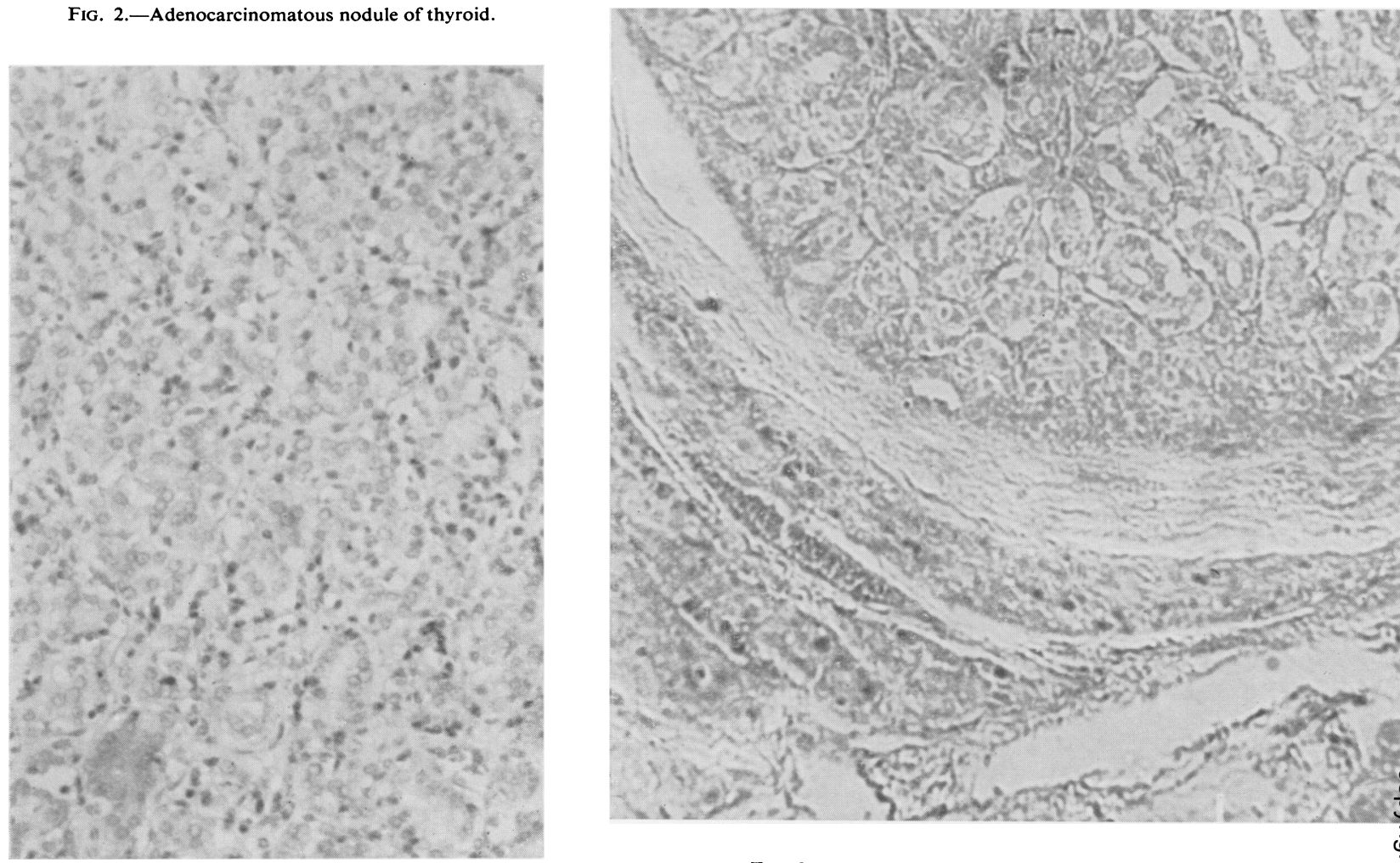

FIG. 3.-Adenocarcinomatous area of thyroid.

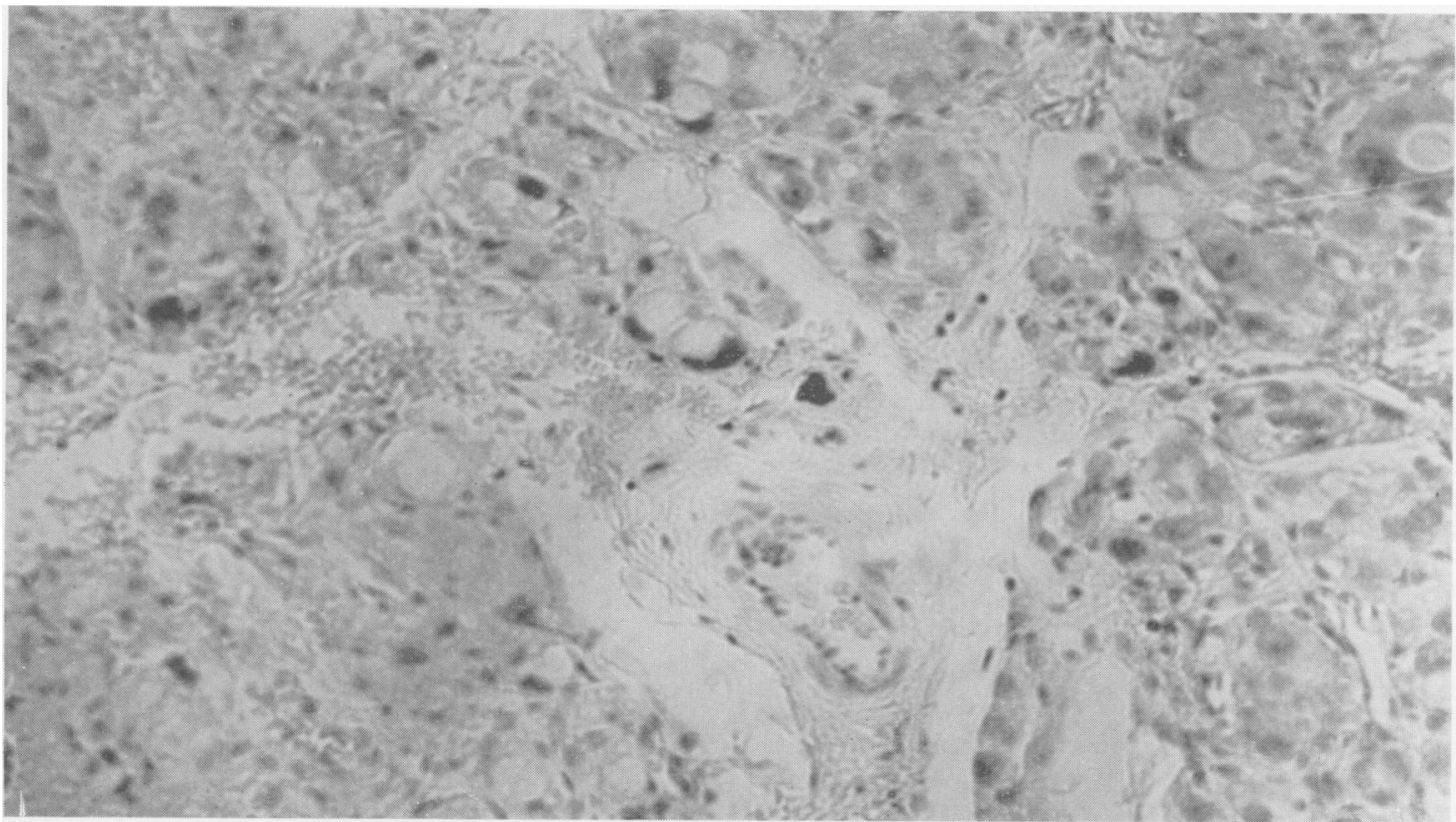


The boy's respirations had become noisy and he tired easily.

There was a diffuse, nodular swelling, $4 \mathrm{~cm}$. by $3 \mathrm{~cm}$., in the left lobe of the thyroid gland, with a solitary nodule, $1.5 \mathrm{~cm}$. in diameter, in the isthmus. The right lobe was slightly enlarged but was not nodular. The swellings felt cystic. The lymph nodes were not enlarged and there were no signs of toxicity. It was decided to explore the swelling.

On August 21, 1952, under endotracheal nitrous oxide, oxygen and ether anaesthesia, the thyroid was explored through the usual collar incision with division of the left infrahyoid muscles. The pyramidal lobe contained a cyst, and the left lobe contained numerous small hard nodules with one larger cyst. The right lobe contained a few small nodules. As the nature of these was still in doubt, most of the left lobe was removed, about onequarter being left, and the pyramidal lobe and most of the isthmus were also excised.

Pathological Report. The specimen was a lobe of thyroid gland, 4.75 by 2.5 by $1.5 \mathrm{~cm}$., pink and soft. On the cut surface several sharply demarcated yellowish-pink nodules, $1-1.5 \mathrm{~cm}$., in diameter, were seen, together with a pea-sized cyst lined by smooth, white membrane.

Histology. Three different types of tissue were present: (1) Normal thyroid tissue with slight papilliform proliferation of the epithelium; (2) tissue consisting of solid cords of cubical or low columnar cells with a vesicular nucleus and an abundant vacuolated cytoplasm, and vesicles with a minute lumen and a lining of similar cells. In this area were groups of smaller cells with dark nuclei (Fig. 1); (3) solid cords of cells, larger than those in area (2), with large nuclei varying in shape, usually hyperchromatic, sometimes multiple, and small vesicles lined by the same type of cells. Mitoses, sometimes atypical, were not uncommon in this area (Figs. 2 and 3).

The cyst was lined partly by tissue of type (2), partly by fibrous tissue with a patch of calcification, and neoplastic tissue of type (2) and (3) was present within the capsule.

The findings were consistent with the diagnosis of adenocarcinoma of the thyroid. Accordingly, the chest and long bones were radiographed, but no secondary deposits could be seen.

Second Operation. On August 28, under endotracheal nitrous oxide, oxygen and ether anaesthesia, the wound was re-opened and the infrahyoid muscles divided. The recurrent laryngeal nerves were dissected and preserved, and the right lobe with the remains of the left lobe and the isthmus removed.

The macroscopic and histological appearances were the same as in the previous specimen.

The boy was referred to Mr. W. H. Bond at the Queen Elizabeth Hospital, Birmingham, for radiotherapy. He was given tracer dosage only of 250 micro-curies of $I^{131}$ on September 8, 1952. One hundred per cent. of the dose was excreted and no residual activity was found to Geiger counting. Subsequently a course of radiotherapy was given by simple opposed fields of a central dose of
$3,000 \mathrm{r}$ in 15 treatments over three weeks, with insignificant reactions.

The boy has been followed up as an out-patient and has remained well on a maintenance dose of 8 grains of thyroid weekly. When last seen in May, 1956, the growth had not recurred.

\section{Comment}

Taylor and Wilkinson (1935) stated that on clinical grounds thyroid carcinoma in childhood could be divided into two groups, namely (1) relatively benign, slowly growing tumours, without infiltration or glandular invasion. The diagnosis as a rule was made histologically, and the appearances were those of a malignant adenoma. (2) Rapidly growing tumours with early invasion of the neck tissues, trachea and lymph nodes, and distant metastases; histologically the appearances were those of papilliferous adenocarcinoma.

Winship (1951), in an extensive review of cases in childhood, found 93 reported in the literature, added four of his own, and collected 95 further unpublished cases from various centres of North America. The first sign of disease in most cases was a painless lump in the neck, usually in the thyroid gland, but occasionally in its lymphatic drainage area. Few children had symptoms of advanced thyroid carcinoma, e.g., dysphagia or dyspnoea. The patients in his series had treatment varying from surgery alone to radiotherapy alone. Fifty-three per cent. had surgery supplemented by radiotherapy. A sufficient time has not yet elapsed for the various forms of treatment to be evaluated, but he felt that the first operative treatment, if sufficiently radical, offered the best chance of cure.

\section{Summary}

Reports of thyroid carcinoma in children in Great Britain are reviewed, and the case is described of a boy of 9 years, treated by total thyroidectomy and radiotherapy, alive and well three years and nine months after operation. The clinical features of such tumours are briefly discussed.

I am indebted to Mr. R. K. Debenham for permission to treat this child and publish the report, and to $\mathrm{Mr}$. W. H. Bond for the post-operative radiotherapy. My thanks are also due to Dr. Frances Braid for her assistance in stabilizing the thyroid dosage, to Dr. H. S. Baar for the pathological examination and to Mr. J. G. Williamson for the photography.

\section{REFERENCES}

d'Abreu, A. L. (1936). Personal communication.

East J. A. (1954). Personal communication from Mr. J. A. East and Dr. J. W. Whittick.

Goldie, W. (1950). Personal communication from Dr. Georgiana Bonser.

Hughes, B. (1920). Brit. med. J., 1, 362.

Joll, C. A. (1936). Personal communication from Mr. A. H. Hunt and Dr. J. W. Whittick.

Moncrieff, A. and Poynton, F. J. (1929). Proc. rov. Soc. Med., 23, 109. Taylor, A. B. and Wilkinson, B. M. (1935). Archives of Disease in Childhood, 10, 99.

Winship, T. (1951). Trans. Amer. goiter Ass., p. 364.

Winship, T. (1950, W. W. (1953). Arch. chir. neerl., 5, 253. 